\title{
Comparação do valor nutritivo de farinhas de sangue e de farinhas de vísceras para suínos utilizando-se o método da proteína e gordura digestíveis e o método de substituição
}

\author{
João Dionísio Henn ${ }^{1}$, Andréa Machado Leal Ribeiro², Alexandre de Mello Kessler ${ }^{2}$ \\ ${ }^{1}$ Mestrando em Zootecnia da UFRGS. \\ 2 Departamento de Zootecnia - Faculdade de Agronomia da Universidade Federal do Rio Grande do Sul - Porto Alegre, RS.
}

RESUMO - Foram realizados dois experimentos com suínos de 49 e $65 \mathrm{~kg}$ (experimentos 1 e 2, respectivamente) para determinação dos valores de energia digestível (ED) de três farinhas de sangue (experimento 1): convencional (FSC), flash dried (FSFD) e células vermelhas spray dried (CVSD) e de três farinhas de vísceras (experimento 2): FV10,1; FV12,7 e FV16,7\% de cinzas) por um método alternativo ao método de substituição (MSb). O método consistiu da substituição do amido da dieta basal por níveis crescentes do ingrediente-teste (7 e 14\%). Os coeficientes de digestibilidade da proteína (CDPB) e da gordura (CDGB) foram obtidos por meio de análise de regressão entre a porcentagem de PB (ou GB) adicionada à dieta basal e a porcentagem de proteína digestível (ou gordura digestível) da dieta. Os ensaios de digestibilidade foram feitos por meio da coleta total de fezes durante cinco dias, após quatro dias de adaptação. Também foi constituído um tratamento com substituição de $25 \%$ de FSC ou FV-10,1\% à dieta basal para determinação da ED pelo MSb. Os CDPB, ED e EMA foram $30 \%, 1.432$ e $1.246 \mathrm{kcal} / \mathrm{kg}$ para FSC; 86,7\%, 4.185 e $3.648 \mathrm{kcal} / \mathrm{kg}$ para FSFD e 84,6\%, 4.041 e $3.512 \mathrm{kcal} / \mathrm{kg}$ para CVSD. Houve diferença nas curvas de regressão entre a FSC e as outras fontes. A ED da FSC pelo MSb foi de $988 \pm 268 \mathrm{kcal} / \mathrm{kg}$. Para as FV-10,1; FV12,7 e FV-16,7, os CDPB, CDGB, ED e EMA foram, respectivamente, de 93,0; 87,6; 4.106; 3.719; 96,4; 85,6; 4.390; e 3.987 e $84,3 \%, 80,5 \% ; 3.925$ e $3.580 \mathrm{kcal} / \mathrm{kg}$. Para o CDPB, houve diferença significativa entre as inclinações de regressão da FV-16,7, em comparação às outras fontes. Para os CDGB, não houve diferença significativa entre as inclinações. O valor de ED da FV-10,1, pelo MSb, foi $4.057 \pm 164 \mathrm{kcal} / \mathrm{kg}$. É provável que o MSb subestime a ED de ingredientes de pouca palatabilidade, como as farinhas de sangue. O método alternativo apresenta-se como boa opção no cálculo da ED.

Palavras-chave: digestibilidade, gordura, farinhas de sangue, farinhas de vísceras, proteína

\section{Comparison of digestible energy of blood meals and poultry by-product meals for pigs using the digestible protein and fat method and the replacement method}

\footnotetext{
ABSTRACT - Two experiments (EXP) were carried out with 49 and $65 \mathrm{~kg}$ barrows (EXP 1 and 2, respectively) to determine digestible energy (DE) values of three sources of blood meals (EXP 1): conventional (CBM), flash dried (FDBM) and spray dried red blood cells (SDRBC), and of three poultry by-product meals (EXP 2) (PBM-10.1, PBM-12.7, and PBM-16.7\% of ash content) by an alternative method to the replacement method ( $\mathrm{SbM})$. The method was based on the starch basal diet replacement with increasing levels of ingredient test (7 and 14\%). Digestibility coefficients of protein (DCP) and fat (DCF) were obtained by the regression analysis between the percentage of added protein (or fat) in the basal diet and the dietary digestible protein (or digestible fat) percentage. Total feces collection was performed, during 5 days, for the digestibility assays, after 4 days of adaptation. Another treatment consisted of starch basal diet replacement with 25\% of CBM or PBM-10.1 to determine DE by SbM. The DCP, DE and AME were of 30\%, 1,432, and 1,246 kcal/kg for CBM; 86.7, 4.185, and 3,648 $\mathrm{kcal} / \mathrm{kg}$ for FDBM and $84.6 \%, 4,041$, and $3.512 \mathrm{kcal} / \mathrm{kg}$ for SDRBC, respectively. Regression lines difference was found between CBM and the other two sources. DE of CBM measured by SbM was of $988 \pm 268 \mathrm{kcal} / \mathrm{kg}$. For PBM-10.1, PBM-12.7 and PBM-16.7, DCP, DCF, DE and AME were, respectively, 93.0, 87.6, 4,106, 3,719, 96.4, 85.6, 4,390, and 3,987 and 84.3\%, 80.5\%, 3,925, and $3,580 \mathrm{kcal} / \mathrm{kg}$. Regression lines difference was found between PBP-16.7 and the other two sources for DCP. For DCF lines,

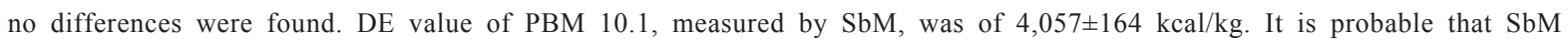
underestimate ingredient DE, specially for those with little palatability, as blood meals. The alternative method is a good option for DE calculations.
}

Key Words: blood meal, digestibility, fat, poultry by-product meal, protein 


\section{Introdução}

Os valores de energia dos subprodutos de origem animal são altamente variáveis entre as fontes, e estas variações são facilmente explicadas pela forma de processamento e pelo tipo e a proporção dos diferentes tecidos animais que compõem estes subprodutos (Knabe et al., 1989; Penz Jr. et al., 1999). Grande parte da variação na digestibilidade da energia destes alimentos está associada às frações protéica e de gordura, que apresentam digestibilidades diferentes (Noblet \& Perez, 1993). Entretanto, a variação na digestibilidade da proteína e da gordura não tem sido considerada nas equações de predição dos valores de energia a partir dos valores de composição química desses produtos, acarretando subestimação dos valores de energia quando a qualidade e a digestibilidade destas matérias-primas é maior.

As tabelas de composição de alimentos, como as do NRC (1994) e NRC (1998), apresentam valores de energia inferiores ao esperado quando calculados pela soma da energia da proteína e da gordura digestíveis das farinhas de origem animal, o que é fundamentado na metodologia de medição da energia utilizada, pois as farinhas de sangue (FS) e de vísceras (FV) não podem ser incluídas em altos níveis (30 a 40\%) em ensaios tradicionais de determinação de valores energéticos por substituição, pois interferem na eficiência digestiva dos animais.

De acordo com Campbell et al. (1983), em ensaios de metabolizabilidade, quando o nível de inclusão do ingrediente-teste constitui pequena fração da dieta fornecida aos animais, a multiplicação do erro pode ser substancial. Em contraste com as medições em ensaios tradicionais, a ED e a EM das FS e das FV podem ser estimadas pela soma das energias da proteína e da gordura disponíveis destas fontes, em ensaios de baixa inclusão, semelhante à metodologia utilizada para aves na estimativa da EM de óleos e gorduras (Mateos \& Sell, 1980; Wiseman \& Salvador, 1989). Objetivou-se com este trabalho determinar os valores de ED de FS e de FV para suínos, com base no método da proteína e da gordura digestíveis, comparando-o ao método clássico de substituição.

\section{Material e Métodos}

Foram realizados dois experimentos no Laboratório de Ensino Zootécnico da Faculdade de Agronomia da Universidade Federal do Rio Grande do Sul. O primeiro experimento foi constituído por dois ensaios de metabolismo com farinhas de sangue. Foram utilizados 34 suínos machos castrados (17 em cada ensaio) da linhagem comercial JSR, com peso inicial de 49,6 $88,1 \mathrm{~kg}$. Os animais foram alojados individualmente em gaiolas metálicas semelhantes ao modelo descrito por Pekas (1968), de modo que os suínos dos tratamentos apresentassem peso médio similar no início do período experimental.

Foi utilizado o delineamento experimental em blocos ao acaso, sendo o critério de blocamento o ensaio (ensaios 1 e 2), com oito tratamentos e quatro repetições, à exceção do tratamento composto pela dieta basal, sem a inclusão do ingrediente-teste (T1), constituído de seis repetições.

O T1 foi comum para as três fontes de farinha de sangue. As três fontes de farinha de sangue avaliadas foram: convencional (FSC), flash dried (FSFD) e células vermelhas do sangue spray dried (CVSD), cujas composições bromatológicas e energéticas são apresentadas na Tabela 1.

A FSC é o produto do cozimento e da desidratação do sangue fresco em secadores rotatórios. É submetida à elevada temperatura, por tempo prolongado, reduzindo sua qualidade, apresentando problemas de palatabilidade quando utilizada em altos níveis. Na FSFD, a água é removida por processo mecânico ou condensada por cocção até estado semi-sólido. Esta massa é, então, transferida para um secador rápido a fim de remover a umidade restante. As CVSD resultam da coagulação e centrifugação do sangue, com remoção do plasma sangüíneo. A umidade é removida por evaporação em baixa temperatura, sob vácuo. Essa massa é então jogada, em forma de spray, em um equipamento com corrente de ar quente para reduzir a umidade até, no máximo, $8 \%$ (Bellaver, 2001).

Cada uma das três farinhas de sangue substituiu $7 \mathrm{e}$ 14\% do amido da dieta basal (Tabela 3). Além desses tratamentos, foi constituído um tratamento (T8) com inclusão de $25 \%$ de FSC na dieta basal, para determinação da ED pelo método de substituição.

\begin{tabular}{|c|c|c|c|c|c|}
\hline Ingrediente & MS & PB & $\mathrm{GB}^{1}$ & MM & EB \\
\hline \multirow[t]{2}{*}{ Ingredient } & $D M$ & $C P$ & $C F$ & Ash & $G E$ \\
\hline & & & & - & $(\mathrm{kcal} / \mathrm{kg})$ \\
\hline $\mathrm{FSC}^{2}$ & 95,7 & 84,5 & 1,0 & 3,2 & 4.732 \\
\hline FSFD $^{3}$ & 91,0 & 85,3 & 0,4 & 1,8 & 4.930 \\
\hline $\mathrm{CVSD}^{4}$ & 92,2 & 84,4 & 0,5 & 3,6 & 4.763 \\
\hline
\end{tabular}

* Valores expressos na matéria natural (Values as-fed basis).

1 Gordura bruta (Crude fat); ${ }^{2}$ Farinha de sangue convencional (Conventional blood meal); ${ }^{3}$ Farinha de sangue flash dried (Flash dried blood meal); ${ }^{4}$ Células vermelhas spray dried (Spray dried blood meal). 
O segundo experimento foi composto por dois ensaios de metabolismo com farinhas de vísceras de aves. A metodologia utilizada foi idêntica à do primeiro experimento, sendo utilizados suínos com peso médio de $65,7 \pm 6,1 \mathrm{~kg}$.

Foram avaliadas três fontes de farinhas de vísceras: farinha de vísceras contendo $16,7 \% \mathrm{MM}(\mathrm{FV}-16,7)$, farinha de vísceras contendo $12,7 \% \mathrm{MM}(\mathrm{FV}-12,7)$ e farinha de vísceras contendo 10,1\% MM (FV-10,1), cujas composições bromatológicas e energéticas são apresentadas na Tabela 2.

Cada uma das três fontes de farinha de vísceras substituiu 7 e 14\% do amido da dieta basal, cuja composição foi igual à da dieta utilizada no experimento 1 (Tabela 3), alterando apenas o alimento-teste. Também foi constituído um tratamento (T8) com inclusão de $25 \%$ de FV-10,1 na dieta basal, para determinação da ED pelo método de substituição.

Em ambos os experimentos, os ingredientes-teste foram analisados previamente no Laboratório de Nutrição Animal da UFRGS.
Os animais foram submetidos a um período de quatro dias de adaptação às gaiolas e às dietas experimentais e, posteriormente, ao período de cinco dias de coleta total de fezes e de urina. As fezes foram coletadas duas vezes ao dia, pesadas e uma alíquota de $20 \%$ do total produzido, em peso, foi acondicionada em saco plástico identificado e armazenada em câmara fria $\left(-10^{\circ} \mathrm{C}\right)$. Foi utilizado como marcador fecal o óxido férrico $\left(\mathrm{Fe}_{2} \mathrm{O}_{3}\right)$, na proporção de $1 \%$ da dieta.

Tabela 2 - Composição das farinhas de vísceras utilizadas no experimento $2^{*}$

Table 2 - Composition of poultry by-product meals used in the experiment 2

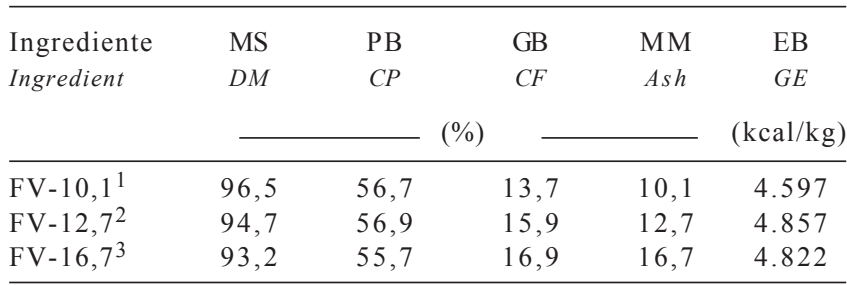

* Valores expressos na matéria natural (Values as-fed basis).

1 Farinha de vísceras com 10,1\% MM (Poultry by-product meal $10.1 \%$ ash).

2 Farinha de vísceras com 12,7\% MM (Poultry by-product meal $12.7 \%$ ash).

${ }^{3}$ Farinha de vísceras com 16,7\% MM (Poultry by-product meal $16.7 \%$ ash).

Tabela 3 - Composição das dietas experimentais

Table 3 - Ingredient composition of the experimental diets

\begin{tabular}{|c|c|c|c|c|c|c|c|c|}
\hline $\begin{array}{l}\text { Ingrediente }(\%) \\
\text { Ingredient }\end{array}$ & T 1 & Т 2 & Т 3 & $\mathrm{~T} 4$ & Т 5 & Т 6 & T 7 & T 8 \\
\hline Milho moído (Corn) & 81,21 & 81,21 & 81,21 & 81,21 & 81,21 & 81,21 & 81,21 & - \\
\hline Amido de milho (Corn starch) & 14,00 & 7,00 & 7,00 & 7,00 & 0,00 & 0,00 & 0,00 & - \\
\hline Fosfato bicálcico (Dicalcium phosphate) & 1,68 & 1,68 & 1,68 & 1,68 & 1,68 & 1,68 & 1,68 & - \\
\hline Polpa de beterraba (Sugar beet) & 1,50 & 1,50 & 1,50 & 1,50 & 1,50 & 1,50 & 1,50 & - \\
\hline Calcáreo (Limestone) & 0,86 & 0,86 & 0,86 & 0,86 & 0,86 & 0,86 & 0,86 & - \\
\hline Sal comum (Salt) & 0,41 & 0,41 & 0,41 & 0,41 & 0,41 & 0,41 & 0,41 & - \\
\hline Cloreto colina 60 (Choline chloride) & 0,14 & 0,14 & 0,14 & 0,14 & 0,14 & 0,14 & 0,14 & - \\
\hline Premix mineral $(\text { Mineral mix })^{\mathrm{a}}$ & 0,10 & 0,10 & 0,10 & 0,10 & 0,10 & 0,10 & 0,10 & - \\
\hline Premix vitamínico $(\text { Vitamin mix })^{\mathrm{b}}$ & 0,05 & 0,05 & 0,05 & 0,05 & 0,05 & 0,05 & 0,05 & - \\
\hline Tylan S100 (\%) (Tylan S 100, \%) & 0,05 & 0,05 & 0,05 & 0,05 & 0,05 & 0,05 & 0,05 & - \\
\hline FSC/FV10,1 (Conventional blood meal/PBP10.1) & - & 7,00 & - & - & 14,00 & - & - & 25,0 \\
\hline FSFD/FV12,7 (Flash dried blood meal/PBP12.7) & - & - & 7,00 & - & - & 14,00 & - & - \\
\hline CVSD/FV16,7 (Spray dried red blood cels/PBP16.7) & - & - & - & 7,00 & - & - & 14,00 & - \\
\hline Dieta basal (T1) (Basal diet T1) & - & - & - & - & - & - & - & 75,0 \\
\hline
\end{tabular}

Composição calculada da dieta basal ${ }^{\mathrm{c}}$

Calculated composition

Proteína bruta (\%) (Crude protein)

Energia metabolizável ( $\mathrm{kcal} / \mathrm{kg}$ ) (Metabolizable energy)

Amido (\%) (Starch)

Fibra bruta (\%) (Crude fiber)

Gordura total (\%) (Total fat)

Cálcio (\%) (Calcium)

Fósforo disponível (\%) (Available phosphorus)

Sódio (\%) (Sodium)

Colina ( $\mathrm{mg} / \mathrm{kg})$ (Choline)
6,54
3.299
50,34
2,65
2,85
0,70
0,36
0,20
1.200

a Premix mineral para suínos: Composição por kg de ração (Composition per $\mathrm{kg}$ of diet): $\mathrm{Fe}=126 \mathrm{mg} ; \mathrm{Zn}=210 \mathrm{mg} ; \mathrm{Mn}=84 \mathrm{mg} ; \mathrm{Cu}=21 \mathrm{mg} ; \mathrm{I}=0,31 \mathrm{mg}$; $\mathrm{Se}=0,42 \mathrm{mg}$.

b Premix vitamínico para suínos: Composição por kg de ração (Composition per kg of diet): vit. $\mathrm{A}=10.500,00$ UI; vit. $\mathrm{D}_{3}=2.100,00$ UI; vit. E = 21,00 mg; vit. $\mathrm{K}_{3}=2,10 \mathrm{mg}$; vit. $\mathrm{B}_{2}=6,20 \mathrm{mg}$; vit. $\mathrm{B}_{6}=1,10 \mathrm{mg}$; vit. $\mathrm{B}_{12}=0,031 \mathrm{mg}$; ácido pantotênico (patothenic acid) $=16,80 \mathrm{mg} ;$ niacina (niacin) $=31,50 \mathrm{mg} ;$ ácido fólico (folic acid) = 0,6 mg; biotina (biotin) $=0,050 \mathrm{mg}$.

c Valores obtidos a partir da composição dos ingredientes descrita por Rostagno (2000)

$c$ Values obtained from Rostagno et al. (2000) tables. 
No final do período experimental, as fezes foram descongeladas e homogeneizadas, sendo retirada uma amostra de aproximadamente $300 \mathrm{~g}$ para as análises laboratoriais.

Após a amostragem das fezes (duas vezes ao dia), a urina foi coletada e o volume total produzido foi pesado e homogeneizado, sendo coletada uma alíquota de 5\%, em peso, por repetição. Esta alíquota foi armazenada em câmara fria $\left(-10^{\circ} \mathrm{C}\right)$ e, ao final do período de coleta, foi descongelada e homogeneizada, sendo retirada uma amostra de $100 \mathrm{~mL}$ para as análises de N. O início e o final do período de coleta de urina foram determinados, respectivamente, pelo fornecimento da primeira e da última refeição do período experimental. Para reduzir o $\mathrm{pH}$ e evitar a perda de $\mathrm{N}$-urinário via formação de amônia, diariamente foram adicionados ao balde de urina $20 \mathrm{~mL}$ de $\mathrm{H}_{2} \mathrm{SO}_{4}$.

As dietas experimentais foram fornecidas em duas refeições diárias, às 9 e 18 h. Em cada refeição foram oferecidos $900 \mathrm{~g}$ das dietas, correspondentes a aproximadamente 2,82 e 2,31 vezes a exigência de mantença dos animais, nos experimentos 1 e 2 respectivamente, utilizando-se a estimativa de $112 \mathrm{kcal} \mathrm{EM} / \mathrm{kg}$ PM (Noblet et al., 1989). As sobras de ração foram coletadas, secas e subtraídas do total fornecido para estabelecimento do volume absoluto consumido. Diariamente, foi coletada uma amostra de cada dieta, representativa das refeições consumidas no dia. A água foi fornecida à vontade em bebedouro automático tipo concha.

As dietas experimentais, as farinhas de sangue e de vísceras e as fezes foram submetidas às análises de MS, PB, GB por hidrólise ácida (AOAC, 1993) e EB (Parr Instruments Co, 1994). Na urina foram determinados os teores de $\mathrm{Ne}$ EB como 9,17 kcal/g de N (Morgan et al., 1975), em que $\mathrm{N}=$ nitrogênio $(\mathrm{g})$ contido na urina produzida durante o período de coleta.

Para a FSC foram determinados os coeficientes de digestibilidade aparente da matéria seca (CDMS), da energia bruta (CDEB) e da proteína bruta (CDPB) e os valores de ED e EM, pelo método de substituição, de acordo com as fórmulas desenvolvidas por Matterson et al. (1965).

Pelo método da proteína e gordura digestíveis, o CDPB para cada ingrediente-teste foi calculado por meio de análises de regressão, tendo como variável independente (X) o percentual de $\mathrm{PB}$ adicionado à dieta e como variável dependente $(\mathrm{Y})$ o percentual de proteína digestível da dieta. A inclinação da reta correspondeu ao CDPB do ingredienteteste e o valor do intercepto representou o valor de PD da dieta basal.

O coeficiente de digestibilidade da gordura das FV também foi calculado da mesma forma, tendo como variável independente $(\mathrm{X})$ o percentual de gordura bruta adicionado à dieta e, como variável dependente $(\mathrm{Y})$, o percentual de gordura digestível da dieta. A determinação da GD das farinhas de sangue não foi possível, em razão dos baixos níveis desta fração no ingrediente. Os valores de PD e GD utilizados nas análises de regressão foram obtidos pelo método de coleta total.

A energia digestível das fontes estudadas foi calculada por meio das seguintes fórmulas:

ED da farinha de sangue $=\mathrm{PB}$ do ingrediente-teste $*$ CDPB do ingrediente-teste * EB (valor calórico) da proteína $(5.660 \mathrm{kcal} / \mathrm{kg})$.

$\mathrm{ED}$ da farinha de vísceras $=\mathrm{PB}$ do ingrediente-teste * CDPB do ingrediente-teste * EB da proteína $(5.660 \mathrm{kcal} / \mathrm{kg})$ + GB do ingrediente $*$ CDGB do ingrediente * EB da gordura $(9.400 \mathrm{kcal} / \mathrm{kg})$.

Também foram estimados os valores de EM das farinhas de sangue e das farinhas de vísceras, considerando retenção protéica de $50 \%$ (Kessler, 2004), sendo a EM=ED - EU (energia perdida na urina), em que: $\mathrm{EU}=\mathrm{PD}$ ( $\mathrm{g} \mathrm{N}$ do ingrediente $) *(100-50 \%$ de retenção), considerando perda de $9,17 \mathrm{kcal} / \mathrm{g}$ de $\mathrm{N}$ na urina (Morgan et al. 1975).

\section{Resultados e Discussão}

Na Figura 1 são representadas graficamente as retas e as equações resultantes da regressão entre a porcentagem de PB adicionada (\% do ingrediente adicionado * PB do ingrediente) e a de proteína digestível da dieta. Nas equações, o valor de "b" representa o coeficiente de digestibilidade da proteína do ingrediente-teste, ou seja, das farinhas de sangue.

Os CDPB foram de $30,0 \%$ para a FSC, $86,7 \%$ para a FSFD e $84,6 \%$ para a CVSD (Figura 1). Foi detectada diferença $(\mathrm{P}<0,001)$ nas inclinações entre a FSC e as outras fontes (FSFD e CVSD). Não houve diferença estatística entre os interceptos. Estes CDPB são inferiores aos obtidos por Knabe et al. (1989), que, utilizando a metodologia de substituição, com três farinhas de sangue "ring dried" (semelhante ao spray dried), obtiveram CDPB de 88, 88 e $91 \%$. Para a FSC, Ferreira et al. (1997), observaram CDPB médio de 55,25\%.

$\mathrm{Na}$ Tabela 4 encontram-se os valores de ED calculada pelo método da proteína digestível e os valores estimados de EM das farinhas de sangue. A ED foi de $1.432 \mathrm{kcal} / \mathrm{kg}$ para a FSC, $4.185 \mathrm{kcal} / \mathrm{kg}$ para a FSFD e de $4.041 \mathrm{kcal} / \mathrm{kg}$ para a CVSD, valores expressos na matéria natural (MN). Ferreira et al. (1997), para a FSC, obtiveram ED de 4.324 e EM de $4.026 \mathrm{kcal} / \mathrm{kg}$ na MS. Rostagno et al. (2000) encontraram valores de ED de 3.381 e EM de $3.004 \mathrm{kcal} / \mathrm{kg}$ na MN. O NRC (1998) recomenda valor de ED para a FSFD 


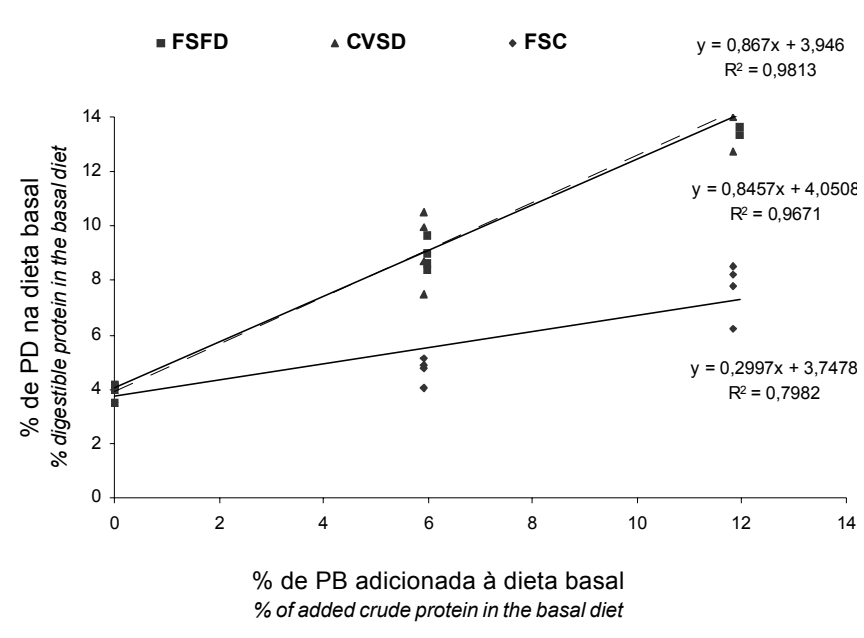

Figura 1 - Linhas de regressão da proteína digestível (PD) das fontes de farinha de sangue testadas.

Figure 1 - Regression lines of digestible protein of tested blood meals.

Tabela 4 - Valores de energia digestível (ED) e energia metabolizável $(E M)^{1}$ das farinhas de sangue, obtidos pelo método da proteína e da gordura digestíveis

Table 4 - Digestible energy(DE) and metabolizable energy (ME) values of the blood meals, obtained by the digestible protein and fat method

\begin{tabular}{lcc}
\hline $\begin{array}{l}\text { Ingrediente } \\
\text { Ingredient }\end{array}$ & $\mathrm{ED}(\mathrm{kcal} / \mathrm{kg})$ & $\mathrm{EM}(\mathrm{kcal} / \mathrm{kg})$ \\
& $M E$ & $D E$ \\
\hline FSC & $1.432 \pm 060^{*}$ & 1.246 \\
FSFD & $4.185 \pm 242$ & 3.648 \\
CVSD & $4.041 \pm 167$ & 3.512
\end{tabular}

${ }^{1}$ EM estimada considerando $50 \%$ de retenção protéica. *Erro-padrão da média (Valores expressos na matéria natural).

${ }^{1}$ Estimated ME considering 50\% protein retention. * Mean standard error (Values as-fed basis).

de $2.500 \mathrm{kcal} / \mathrm{kg}$ na $\mathrm{MS}$, que representa $54,4 \%$ do valor obtido pelo método da proteína digestível neste trabalho. Para a FSC, os valores apresentados no NRC (1998) são mais elevados que os obtidos neste trabalho $(3.098 \times 1.496 \mathrm{kcal} /$ $\mathrm{kg}$ na MS). A variabilidade obtida em farinhas de sangue da mesma categoria é resultante das diferenças na matériaprima e/ou nos métodos de processamento ou na combinação destes dois fatores (Knabe et al., 1989). Até para o mesmo tipo de processamento, parâmetros de operação específicos podem não ser os mesmos e ter efeito importante na qualidade da farinha de sangue produzida.

Os valores de EM são influenciados pelo nível de inclusão do alimento protéico na dieta, pelo consumo e pela qualidade da proteína do alimento (May \& Bell, 1971). Segundo esses autores, quando a proteína é fornecida em excesso ou quando é de baixa qualidade, o nitrogênio urinário, associado à desaminação da proteína digestível absorvida em excesso, acarreta redução da EM.

$\mathrm{Na}$ Tabela 4 são apresentados os valores de EM estimados, que, considerando as características das dietas avaliadas, tanto pelo balanceamento nutricional, em função do nível de inclusão do ingrediente-teste, como pelo nível de consumo, não foram adequados para a medição desse parâmetro. Morgan et al. (1975) sugeriram que a retenção de nitrogênio é de $30 \%$ do N-total ingerido em suínos em crescimento. Nos genótipos de suínos atuais, entretanto, ocorre maior deposição de carne magra, em detrimento à deposição de gordura.

Considerando um padrão de $50 \%$ de retenção de N, os valores estimados de EM, para a FSC, FSFD e CVSD, foram de $1.246 ; 3.648$ e $3512 \mathrm{kcal} / \mathrm{kg}$, respectivamente. Para a FSC, o valor de EM obtido pelo método de substituição foi de $860 \pm 239 \mathrm{kcal} / \mathrm{kg}$. Para o mesmo tipo de FS, Rostagno et al. (2000) propuseram valor médio muito superior, equivalente a $3.004 \mathrm{kcal} / \mathrm{kg}$, enquanto Ferreira et al. (1997) sugeriram $3.562 \mathrm{kcal} \mathrm{EM} / \mathrm{kg}$, ambos os valores expressos na MN.

A ED da FSC medida pelo método de $25 \%$ de substituição foi de $988 \pm 268 \mathrm{kcal} / \mathrm{kg}$, que representa apenas $69 \%$ da ED calculada pelo método da proteína digestível, mostrando subestimação dos valores de ED da FSC medida pelo primeiro método. Neste método, os ingredientes-teste normalmente substituem 30 a $40 \%$ da dieta-referência. Como farinhas de sangue não podem ser incluídas em altos níveis por interferirem na eficiência digestiva e no consumo, podem ocorrer dois resultados: para baixos níveis de inclusão do ingrediente-teste, pequenos erros na determinação dos valores de energia podem ser multiplicados no resultado final; o baixo consumo de um alimento-teste tende a subestimar sua EMA pelo fato de as perdas endógenas aumentarem sua representação nas fezes excretadas (Schneider \& Flatt, 1975).

No experimento com as farinhas de vísceras, os coeficientes de digestibilidade da gordura bruta (CDGB) foram de 87,6; 85,6 e 80,5, para a FV-10,1; FV-12,7 e FV-16,7, respectivamente (Figura 2). Não foram detectadas diferenças entre as inclinações das regressões lineares $(\mathrm{P}>0,05)$, assim como não houve diferença entre os interceptos. Apesar de não-significativa, houve tendência de redução nos CDGB com o aumento da matéria mineral. Segundo Maynard et al. (1984), os ácidos graxos podem se combinar ao cálcio, assim como o magnésio, para formarem compostos insolúveis, que são excretados nas fezes, diminuindo a digestibilidade das gorduras.

Os coeficientes de digestibilidade da proteína foram de 93,$0 ; 96,4$ e $84,3 \%$, respectivamente, para FV-10,1; FV-12,7 


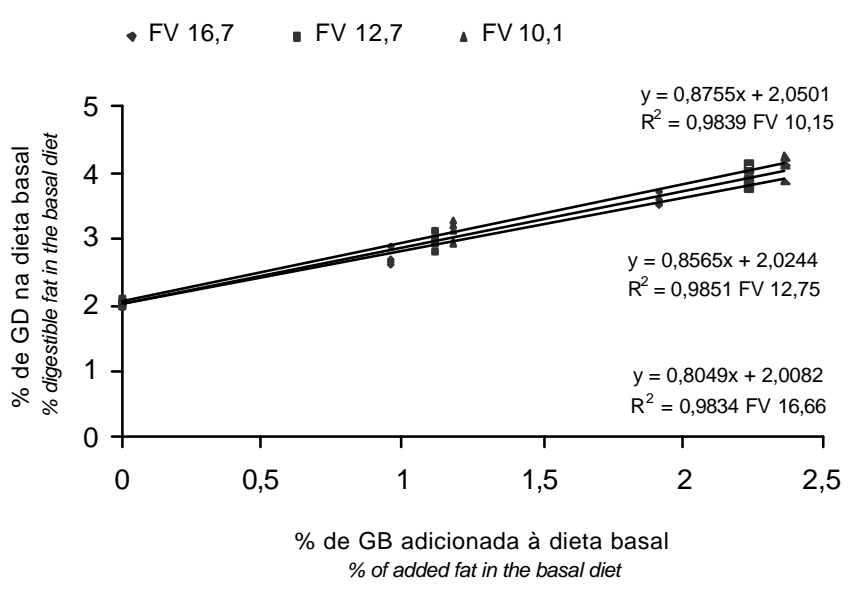

Figura 2 - Linhas de regressão da gordura digestível (GD) das farinhas de vísceras testadas.

Figure 2 - Regression lines of digestible fat of tested poultry by-product meals.

e FV-16,7 (Figura 3). Diferenças entre as inclinações (b) das regressões $(\mathrm{P}<0,05)$ foram obtidas entre a $\mathrm{FV}-16,7$ e as outras duas FV (FV-10,1 e FV-12,7). Não houve diferença entre os interceptos. Knabe et al. (1989) obtiveram coeficiente de digestibilidade da proteína de $87 \%$ para a farinha de vísceras. Estes autores relataram que, além da matériaprima utilizada, o processamento térmico e/ou a combinação destes dois fatores são os grandes responsáveis pelas diferenças entre os coeficientes de digestibilidade dos nutrientes das diferentes farinhas de origem animal.

Os valores calculados de ED para FV-10,1; FV-12,7 e FV-16,7 foram, respectivamente, de $4.106 \pm 126,4.390 \pm 139 \mathrm{e}$ $3.925 \pm 127 \mathrm{kcal} \mathrm{ED} / \mathrm{kg}$ (Tabela 5). O NRC (1998), para a FV com $15,7 \%$ de cinzas, recomenda valores de ED de 3.090 $\mathrm{kcal} / \mathrm{kg}$, muito inferior aos obtidos pelo método da proteína e gordura digestíveis. Rostagno et al. (2000) apresentaram valores de ED para FV $(15,68 \%$ CIN e $11,5 \%$ GB) de 3.790 $\mathrm{kcal} / \mathrm{kg}$

$\mathrm{Na}$ Tabela 5 são apresentados também os valores estimados de EM das farinhas de vísceras, considerando o mesmo padrão de $50 \%$ de retenção de $\mathrm{N}$ utilizado no experimento com farinhas de sangue. Os valores estimados de EM foram de 3.719; 3.987 e 3.580 para a FV-10,1; FV-12,7 e FV-16,7, respectivamente. Para a FV-10,1, a EM obtida pelo método de substituição foi de $3.876 \pm 364 \mathrm{kcal} / \mathrm{kg}$. Rostagno et al. (2000) sugeriram valores de 3.528 e 4.106 $\mathrm{kcal} \mathrm{EM} / \mathrm{kg}$ para as farinhas de vísceras de baixa e alta quantidade de gordura, respectivamente. O NRC (1998) apresenta $3.075 \mathrm{kcal} \mathrm{ED/kg}$ para a farinha de vísceras.

O valor de ED da FV-10,1, calculado pelo método de substituição de $25 \%$, foi de $4.057 \pm 164 \mathrm{kcal} / \mathrm{kg}$, muito seme-

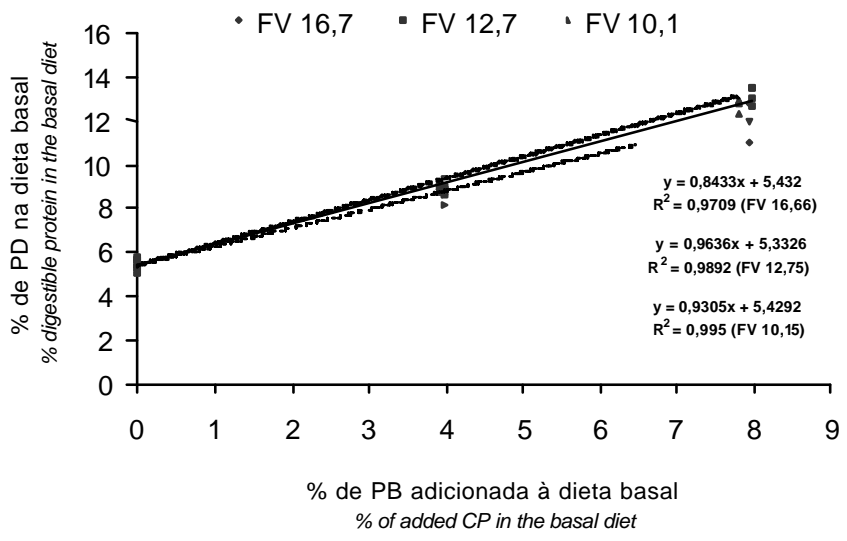

Figura 3 - Linhas de regressão da proteína digestível (PD) das farinhas de vísceras testadas.

Figure 3 - Regression lines of digestible protein tested poultry by-product meals.

Tabela 5 - Valores de energia digestível (ED) e energia metabolizável $(E M)^{1}$ das farinhas de vísceras, obtidos pelo método da proteína e da gordura digestíveis

Table 5 - $\quad D E$ and ME values of the poultry by-product meals, obtained by the digestible protein and fat method

\begin{tabular}{lcc}
\hline $\begin{array}{l}\text { Ingrediente } \\
\text { Ingredient }\end{array}$ & $\mathrm{ED}(\mathrm{kcal} / \mathrm{kg})$ & $\mathrm{EM}(\mathrm{kcal} / \mathrm{kg})$ \\
\hline $\mathrm{FV}-10,1$ & $D E$ & $M E$ \\
$\mathrm{FV}-12,7$ & $4.106 \pm 126^{*}$ & 3.719 \\
$\mathrm{FV}-16,7$ & $4.390 \pm 139$ & 3.987 \\
\hline
\end{tabular}

1 EM estimada considerando $50 \%$ de retenção protéica. *Erro-padrão da média (valores expressos na matéria natural).

${ }^{1}$ Estimated ME considering $50 \%$ protein retention. * Mean standard error (Values asfed basis).

lhante ao obtido pelo método da proteína e gordura digestíveis $(4.106 \pm 191 \mathrm{ED} / \mathrm{kg}$ ), ao contrário do que ocorreu com a farinha de sangue convencional. Entretanto, o erropadrão da média pelo método de substituição foi maior. Pozza et al. (1999) avaliaram cinco farinhas de vísceras para suínos e obtiveram valores de ED de 3.280 a $4.567 \mathrm{kcal} / \mathrm{kg}$.

É importante ressaltar, no entanto, que o método de substituição, neste caso, foi feito com a farinha de vísceras de melhor qualidade, ao contrário dos ensaios envolvendo a farinha de sangue. Além disso, a inclusão de farinha de vísceras na ração-referência não resultou em baixo consumo pelos leitões, ao contrário das farinhas de sangue.

\section{Conclusões}

O método da proteína e gordura digestíveis apresentou-se como boa alternativa no cálculo da energia digestível de ingredientes que não podem ser adicionados em altos níveis em dietas para suínos pelo método de substituição, pois 
aumenta a importância nos ingredientes de menor palatabilidade e qualidade, como a farinha de sangue convencional. Principalmente para este tipo de ingrediente, o método de substituição pode subestimar os valores de energia.

\section{Literatura Citada}

ASSOCIATION OF OFFICIAL AGRICULTURAL CHEMISTS - AOAC. Official methods and recommended pratices of American oil Chemists Society. 4.ed. Washington, 1993. v.1. Methods.

BELLAVER, C. Ingredientes de origem animal destinados à fabricação de rações. In: SIMPÓSIO SOBRE INGREDIENTES NA AlimentaÇÃo Animal, 2001, Campinas. Anais... Campinas: Colégio Brasileiro de Nutrição Animal, 2001. p.125.

CAMPBELL, G.L.; CAMPBELL, L.D.; BLAIR, R. Calculation of metabolizable energy for ingredients incoporated at low levels into a reference diet. Poultry Science, v.62, n.5, p.705-707, 1983.

FERREIRA, E.R.A.; FIALHO, E.T.; TEIXEIRA, A.S. et al. Avaliação da composição química e determinação dos valores energéticos e equação de predição de alguns alimentos para suínos. Revista Brasileira de Zootecnia, v.26, n.3, p.514-523, 1997.

KESSLER, A.M. Retenção de nitrogênio em suínos em crescimento. Porto Alegre: Universidade Federal do Rio Grande do Sul, 2004. Informação pessoal.

KNABE, D.A.; LARUE, E.J.; GREGG, G.M. et al. Apparent digestibility of nitrogen and amino acids in protein feedstuffs by growing pigs. Journal of Animal Science, v.67, p.441$458,1989$.

MAY, R.W.; BELL, J.M. Digestible and metabolizable energy values of some feeds for growing pig. Canadian Journal of Animal Science, v.51, n.2, p.271-278, 1971.

MATEOS, G.G.; SELL, J.L. True and apparent metabolizable energy value of fat for laying hens: influence of level of use. Poultry Science, v.59, n.3, p. 369-373, 1980.

MATTERSON, L.D.; POTTER, L.M.; STUTZ, N.W. et al. The metabolizable energy of feed ingredients for chickens. Storrs, Connecticut: The University of Connecticut, 1965. p.3-11 (Agricultural Experiment Station, Research, Report, 7).

MAYNARD, L.A.; LOOSLI, J.K.; HINTZ, H.F. et al. Nutrição animal. 3.ed. Rio de Janeiro: Freitas Bastos, 1984. 726p.

MORGAN, D.J.; COLE, D.J.A; LEWIS, D. Energy values in pig nutrition. 1. The relationship between digestible energy, metabolizable energy and total digestible nutrient values of a range of feedstuffs. Journal Agricultural Science, v. 84, p.7-17, 1975 .

NOBLET, J.; KAREGE, C.; DUBOIS, S. Influence of sex and genotype on energy utilization in growing pigs. In: van der HONING, Y.; CLOSE, W.H. (Eds.) Energy and metabolism of farm animals. Pudoc: Wageningen, 1989. p.57-60.
NOBLET, J.; PEREZ, J.M. Prediction of digestibility of nutrients and energy values of pig diets from chemical analysis. Journal of Animal Science, v.71, p.3389-3398, 1993.

NATIONAL RESARCH COUNCIL - NRC. Nutrient requirements of poultry. 9.rev.ed. Washington, D.C.: National Academy Press, 1994. $155 \mathrm{p}$.

NATIONAL RESARCH COUNCIL - NRC. Nutrient requirements of swine. 10.rev.ed. Washington, D.C.: National Academy Press, 1998. $211 \mathrm{p}$.

PARR INSTRUMENTS CO. Instructions for the 1241 and 1242 adiabatic calorimeters. Moline: 1994. 29p. (Parr Manual, $153)$.

PENZ JR., A.M.; KESSLER, A.M.; BRUGALLI, I. Novos conceitos de energia para aves. In: SIMPÓSIO INTERNACIONAL SOBRE NUTRIÇÃO DE AVES, 1999, Campinas. Anais... Campinas: Fundação APINCO de Ciência e Tecnologia Avícolas, 1999. p.1-24.

PEKAS, J.C. Versaible swine laboratory apparatus for physiologic and metabolic studies. Journal of Animal Science, v.27, p.1303-1306, 1968.

PESTI, G.M.; FAUST, L.O.; FULLER, H.L. et al. Nutritive value of poultry by-product meal. 1. Metabolizable energy values as influenced by method of determination and level of substitution. Poultry Science, v.65, p.2258-2267, 1986 (supl. 1).

ROSTAGNO, H.S.; ALBINO, L.F.T.; DONZELE, J.L. et al. Tabelas brasileiras para aves e suínos: composição de alimentos e exigências nutricionais. 2.ed. Viçosa, MG: Editora UFV, 2000. $141 \mathrm{p}$.

POZZA, P.C.; GOMES, P.C.; DONZELE, J.L. et al. Composição química e valores de energia digestível de diferentes farinhas de carne e ossos e de farinhas de vísceras para suínos. In: REUNIÃO ANUAL DA SOCIEDADE BRASILEIRA DE ZOOTECNIA, 36. 1999, Porto Alegre. Resumos... Porto Alegre: Sociedade Brasileira de Zootecnia, 1999. p.221.

SCHNEIDER, B.H.; FLATT, W.P. The evaluation of feeds through digestibility experiments. Athens: The university of Georgia Press, 1975. 423p.

WISEMAN, J.; SALVADOR, F. Influence of age, chemical composition and rate of inclusion on the apparent metabolizable energy of fats fed to broiler chicks. British Poultry Science, v.30, p.653-662, 1989. 